УДК 631.4

\title{
ЭКОЛОГИЧЕСКАЯ ОЦЕНКА ХИМИЧЕСКИХ СВОЙСТВ ПОЧВ ПРИМОРСКОЙ РЕКРЕАЦИОННОЙ ЗОНЫ В ПОСЕЛКЕ ГОРОДСКОГО ТИПА ЯНТАРНЫЙ
}

\author{
О. А. Анциферова, О. Ю. Чиянова
ECOLOGICAL ASSESSMENT OF CHEMICAL PROPERTIES OF SOILS OF THE SEASIDE RECREATIONAL ZONE IN THE URBAN VILLAGE YANTARNY

\author{
O. A. Antsiferova, O. Yu. Chiyanova
}

Исследования проводились в парковой рекреационной зоне, которая расположена вдоль абразионного побережья Балтийского моря в поселке городского типа (пгт) Янтарный Калининградской области. Для диагностики почв были заложены разрезы глубиной 150-250 см. Пробы почв отбирались из каждого горизонта. В образцах почв определялись $\mathrm{pH}$, содержание органического углерода (с последующим пересчетом на гумус), подвижных соединений фосфора, калия, тяжелых металлов $(\mathrm{Cu}, \mathrm{Zn}, \mathrm{Pb}, \mathrm{Cd}, \mathrm{Ni}, \mathrm{Cr}(3+))$ и валовое количество ртути. Реакция среды в профиле почв находилась в интервале от слабокислой до нейтральной. В почвах северо-западной части парка им. М. Беккера обнаружены карбонатные горизонты на глубине свыше 80-100 см. Максимальное количество гумуса в почвах сосредоточено в слое $0-10$ см. В среднем оно равно 3,30 $\pm 0,10 \%$ (пределы варьирования 3,00-4,45 \%). Эти величины являются типичными для лесных почв на супесчаных и песчаных породах в автоморфных условиях региона. Распределение гумуса по профилю зависит от генезиса и варьирует от резко убывающего до равномерно убывающего. В четырех из восьми почвах обнаружены погребенные профили разной сохранности. Содержание органического вещества в гумусовых горизонтах погребенных почв варьирует в пределах от 1,19 до 3,99 \%. Почвы рекреационной зоны содержат очень высокое количество подвижного фосфора (более 250 мг/кг) как в гумусовых горизонтах, так и в почвообразующих породах. Это объясняется примесью фосфоритов и является геохимической особенностью пород Замландского п-ова. Количество подвижного калия максимально в гумусовых горизонтах $(100-278$ мг/кг). Распределение калия по профилю резко убывающее. Почвообразующие песчаные породы имеют очень низкое содержание подвижного калия. Количество тяжелых металлов $\left(\mathrm{Cu}, \mathrm{Zn}, \mathrm{Pb}, \mathrm{Cd}, \mathrm{Ni}, \mathrm{Cr}\left(3^{+}\right)\right)$и валовой ртути ниже предельно-допустимых концентраций.

рекреачионная зона, почвы, $\mathrm{pH}$, гумус, распределение по профилю, подвижные формы фосфора, калия, тяжелых металлов, экологическая оченка

The research has been carried out in a park recreation area, which is located along the abrasion coast of the Baltic sea in the urban village Yantarny of the Kaliningrad region. For soil diagnostics, sections with a depth of $150-250 \mathrm{~cm}$ have been laid. 
Soil samples have been taken from each horizon. $\mathrm{pH}$, organic carbon content (with subsequent conversion to humus), mobile compounds of phosphorus, potassium, heavy metals $(\mathrm{Cu}, \mathrm{Zn}, \mathrm{Pb}, \mathrm{Cd}, \mathrm{Ni}, \mathrm{Cr}(3+))$, and the total amount of mercury have been defined in soil samples. The reaction of the medium in the soil profile is in the range from slightly acidic to neutral. In the soils of the North-Western part of M. Becker Park carbonate horizons at a depth of more than $80-100 \mathrm{~cm}$ have been dicrovered. The maximum amount of humus in soils is concentrated in a layer of $0-10 \mathrm{~cm}$. On average, it is equal to $3.30 \pm 0.10 \%$ (the range of variation is $3.00-4.45 \%$ ). These values are typical for forest soils on sandy loam and sand rocks in automorphic conditions of the region. Distribution of humus in the profile depends on the genesis and varies from sharply decreasing to evenly decreasing. Buried profiles of different preservation were found in four of the eight soils. The content of organic matter in humus horizons of buried soils varies from 1.19 to $3.99 \%$. The soils of the recreational zone contain a very high amount of mobile phosphorus (more than $250 \mathrm{mg} / \mathrm{kg}$ ), both in humus horizons and in soil-forming rocks. This is due to the admixture of phosphorites and is a geochemical feature of the rocks of the Samland Peninsula. The maximum number of mobile potassium is contained in the humus horizon $(100-278 \mathrm{mg} / \mathrm{kg})$. The distribution of potassium in the profile is sharply decreasing. Soil-forming sand rocks have a very low content of mobile potassium. The amount of heavy metals $(\mathrm{Cu}, \mathrm{Zn}, \mathrm{Pb}, \mathrm{Cd}, \mathrm{Ni}, \mathrm{Cr}(3+))$ and gross mercury is below the maximum permissible concentrations.

recreational zone, soils, $\mathrm{pH}$, humus, distribution by profile, mobile forms of phosphorus, potassium, heavy metals, ecological assessment

\section{ВВЕДЕНИЕ}

Исследование парковых зон как компонентов урбанизированных экосистем - важная задача оценки качества окружающей среды [1-4]. Устойчивое функционирование рекреационных парковых зон зависит не только от степени антропогенной нагрузки, но и от свойств почв, которые обеспечивают растительность необходимыми элементами питания и являются центром биогеохимического круговорота веществ. Поэтому необходимо изучать состав и свойства почв, а также проводить их эколого-токсикологическое обследование. Эти данные - важная составляющая экологического паспорта рекреационной зоны.

Цель исследования: провести экологическую оценку основных химических свойств почв рекреационной парковой зоны в пгт Янтарный. Задачи: 1) изучить основные химические свойства, влияющие на плодородие почв ( $\mathrm{pH}$, содержание органического вещества (гумуса), подвижные соединения фосфора и калия); 2) оценить эколого-токсикологическое состояние гумусового горизонта почв по содержанию подвижных форм тяжелых металлов.

\section{ОБЪЕКТЫ И МЕТОДЫ ИССЛЕДОВАНИЙ}

Исследования проведены в парковой зоне, которая вытянута вдоль абразионного побережья Балтийского моря в пгт Янтарный Калининградской области. Для диагностики почв были заложены разрезы глубиной $150-250$ см. Генезис и строение почв описаны нами ранее [5]. Названия почв даны по классификации 2004 г. [6]. Образцы для анализа отбирались из каждого горизонта. Анализы проводились по следующим методикам: $\mathrm{pH}_{\mathrm{H} 2 \mathrm{O}}, \mathrm{pH}_{\mathrm{KCl}}$ - потенциометрически, содер- 
жание органического вещества по Тюрину в модификации Симакова, подвижный фосфор и калий по Кирсанову (ГОСТ Р 54650-2011), валовой азот по Кьельдалю (ГОСТ 26107-84). Подвижные формы тяжелых металлов (ТМ) (Cu, Zn, Pb, Cd, Ni, $\mathrm{Cr}(3+))$ анализировались в соответствии с РД 52.18.289 [7]. Содержание ртути определено по ПНД Ф 16.2.2:2.3:3. 25-02 [8]. Анализ ТМ проведен в ФГБУ «Центр агрохимической службы «Калининградский». Для оценки уровня показателей использованы стандартные и рекомендованные шкалы с учетом природной зоны $[9,10]$.

\section{РЕЗУЛЬТАТЫ И ОБСУЖДЕНИЕ}

Обследование показало, что в рекреационной парковой зоне около $80 \%$ почв являются в той или иной степени антропогенно преобразованными (в результате эрозии, искусственной аккумуляции и перемешивания почвогрунтов). Преобладает легкий гранулометрический состав почв и техногенных почвенных образований (супеси, пески). Реакция среды в профиле почв варьирует от слабокислой до близкой к нейтральной в верхних горизонтах (табл. 1). Слабая выщелоченность на фоне промывного типа водного режима объясняется наличием дополнительного эолового привноса солей с акватории Балтийского моря. В целом $\mathrm{pH}$ гумусовых горизонтов является благоприятным для роста и развития большинства древесных и травянистых видов растений в парковой зоне. На глубине свыше полутора метров реакция среды становится нейтральной, а в карбонатных горизонтах - слабо- и среднещелочной. Из восьми контрольных разрезов карбонаты встречались в пяти [5]. При этом гранулометрический состав карбонатных слоев разнообразный: от плотных неогеновых глин до водно-ледниковых слоистых песков с гравием. В пространстве карбонатные слои приурочены к территории парка им. М. Беккера, к северо-западной его части. Плотные карбонатные неогеновые глины можно наблюдать в обнажениях на стенках оврага и на абразионном берегу.

Мощность гумусовых горизонтов сильно варьирует в зависимости от генезиса почв. В ржавоземах на песках она не превышает 20 см, чаще всего 10-15. Распределение гумуса резко убывающее. В стратоземах и урбиквазиземах (урбаноземах) мощность гумусированной толщи достигает 60-80 см. Содержание гумуса постепенно убывает с глубиной. Бимодальное распределение выражено в профилях с наличием хорошо сохранившейся погребенной почвы (разрезы 448 и 451). Максимальное содержание гумуса во всех почвах приурочено к верхнему слою мощностью 5-10 см. Злаковый покров в парковой зоне способствует формированию дернины. В этом слое и происходит активное накопление гумуса, которое не превышает 5 \%. По классификации и диагностике почв России это соответствует серогумусовым горизонтам [6]. Однако в реальности цвет гумусовых горизонтов варьирует от буро-серого до бурого разных оттенков в зависимости от содержания и качественного состава гумуса. 
Таблица 1. Химические свойства почв рекреационной парковой зоны в пгт Янтарный

Table 1. Chemical properties of the soils of the recreational park zone in the urban village Yantarny

\begin{tabular}{|c|c|c|c|c|c|c|}
\hline \multirow[t]{2}{*}{ Разрез и почва } & \multirow{2}{*}{$\begin{array}{c}\text { Горизонт и глуби- } \\
\text { на, см }\end{array}$} & \multirow[t]{2}{*}{$\mathrm{pH}_{\mathrm{H} 2 \mathrm{O}}$} & \multirow[t]{2}{*}{ Гумус, \% } & \multirow[t]{2}{*}{$\mathrm{C}_{\mathrm{OP \Gamma}}, \%$} & \multicolumn{2}{|c|}{ Подвижные соединения, мг/кг } \\
\hline & & & & & $\mathrm{P}_{2} \mathrm{O}_{5}$ & $\mathrm{~K}_{2} \mathrm{O}$ \\
\hline \multirow{10}{*}{$\begin{array}{l}\text { Разрез 447. ТПО* Урбиква- } \\
\text { зизем серогумусовый супес- } \\
\text { чаный на слоистых карбо- } \\
\text { натных водно-ледниковых } \\
\text { отложениях }\end{array}$} & AYur $1-15$ & 6,3 & 3,21 & 1,86 & 264 & 267 \\
\hline & RYtur $15-30$ & 5,8 & 1,76 & 1,02 & 205 & 127 \\
\hline & RYtur $30-50$ & 5,9 & 1,45 & 0,84 & 183 & 95 \\
\hline & R(B)tur $50-60$ & 6,4 & 1,09 & 0,63 & 224 & 51 \\
\hline & $\mathrm{R}(\mathrm{B}) \operatorname{tur} 60-100$ & 7,1 & 0,28 & 0,16 & 594 & 47 \\
\hline & D1gca $100-130$ & 8,0 & - & $-{ }^{* * *}$ & $--^{* * * *}$ & $-{ }^{* * * *}$ \\
\hline & D1gca $130-147$ & 8,4 & - & - & - & - \\
\hline & D2ca $147-160$ & 8,5 & - & - & - & - \\
\hline & D2ca $160-180$ & 8,4 & - & - & - & - \\
\hline & D2ca $180-190$ & 8,4 & - & - & - & - \\
\hline \multirow{10}{*}{$\begin{array}{l}\text { Разрез 448. ТПО. Урбиквази- } \\
\text { зем серогумусовый супесча- } \\
\text { ный на погребенной почве } \\
\text { (буроземе супесчаном) }\end{array}$} & AYur1 - 10 & 5,9 & 3,76 & 2,18 & 293 & 278 \\
\hline & AYur $10-20$ & 5,5 & 3,03 & 1,76 & 300 & 141 \\
\hline & AYur $20-40$ & 5,5 & 2,51 & 1,45 & 321 & 68 \\
\hline & AYur $40-60$ & 5,5 & 1,66 & 0,96 & 343 & 55 \\
\hline & AYur $60-80$ & 6,5 & 1,89 & 1,10 & 336 & 47 \\
\hline & [A] $80-100$ & 6,6 & 3,99 & 2,31 & 179 & 31 \\
\hline & [B1] $100-116$ & 6,7 & 0,91 & 0,53 & 358 & 44 \\
\hline & [B2] $116-130$ & 6,7 & 0,29 & 0,17 & 446 & 44 \\
\hline & {$[\mathrm{BC}] 130-150$} & 7,3 & 0,19 & 0,11 & - & - \\
\hline & Cca $150-170$ & 7,5 & - & - & - & - \\
\hline
\end{tabular}

*ТПО - техногенное поверхностное образование ${ }^{* *}$ - содержание органического углерода менее или равно $0,1 \%$; ${ }^{* * *}$ - подвижный фосфор и калий в карбонатных горизонтах не определялись 
Продолжение табл. 1

\begin{tabular}{|c|c|c|c|c|c|c|}
\hline 1 & 2 & 3 & 4 & 5 & 6 & 7 \\
\hline \multirow{12}{*}{$\begin{array}{l}\text { Разрез 451. Ржавозем супесчаный на } \\
\text { песках с погребенной почвой }\end{array}$} & AY $1-10$ & 6,9 & 3,57 & 2,07 & 669 & 145 \\
\hline & BFM1 $10-40$ & 5,2 & 0,98 & 0,57 & 642 & 41 \\
\hline & BFM1 $40-60$ & 5,6 & 0,47 & 0,27 & 627 & 38 \\
\hline & C $60-80$ & 6,3 & 0,43 & 0,25 & 654 & 33 \\
\hline & C $80-110$ & 6,8 & 0,22 & 0,13 & 708 & 31 \\
\hline & C $110-120$ & 6,7 & 0,31 & 0,18 & 694 & 31 \\
\hline & C $120-150$ & 7,0 & 0,31 & 0,18 & 690 & 31 \\
\hline & C $150-180$ & 6,9 & 0,24 & 0,14 & 688 & 31 \\
\hline & [A] $180-190$ & 6,8 & 1,19 & 0,69 & 264 & 31 \\
\hline & [A] $190-210$ & 6,7 & 0,60 & 0,35 & 569 & 18 \\
\hline & [B] $210-235$ & Не опр. & 0,50 & 0,29 & 855 & 13 \\
\hline & $\mathrm{C} 235-250$ & Не опр. & 0,19 & 0,11 & 1250 & 13 \\
\hline \multirow{10}{*}{$\begin{array}{l}\text { Разрез 452. Стратозем серогумусовый } \\
\text { супесчаный на погребенном ржавоземе }\end{array}$} & AY (RY) $1-20$ & 5,9 & 3,19 & 1,85 & 350 & 100 \\
\hline & AY (RY) $20-40$ & 6,0 & 1,27 & 0,74 & 227 & 38 \\
\hline & AY (RY) $40-55$ & 6,1 & 1,17 & 0,68 & 264 & 40 \\
\hline & [BFM1] $55-75$ & 6,5 & 0,65 & 0,38 & 588 & 41 \\
\hline & [BFM2] $75-96$ & 6,7 & 0,31 & 0,18 & 875 & 31 \\
\hline & BCf $96-105$ & 6,7 & 0,21 & 0,12 & 940 & 34 \\
\hline & C $105-130$ & 6,7 & - & - & 940 & 31 \\
\hline & $\mathrm{Cf}\left(\mathrm{C}_{2}\right) 130-143$ & 7,1 & - & - & - & - \\
\hline & $\mathrm{C}_{3} \mathrm{ca} 143-154$ & 8,0 & - & - & - & - \\
\hline & $\mathrm{C}_{3} \mathrm{ca} 154-160$ & 8,2 & - & - & - & - \\
\hline
\end{tabular}


Окончание табл. 1

\begin{tabular}{|c|c|c|c|c|c|c|}
\hline 1 & 2 & 3 & 4 & 5 & 6 & 7 \\
\hline \multirow{6}{*}{$\begin{array}{l}\text { Разрез 462. Ржавозем супесчаный на } \\
\text { водно-ледниковых песках }\end{array}$} & AY $0-5$ & 5,9 & 4,45 & 2,58 & 241 & 118 \\
\hline & AY $5-22$ & 5,9 & 1,04 & 0,60 & 250 & 31 \\
\hline & BFM1 $22-56$ & 6,1 & 0,52 & 0,30 & 490 & 28 \\
\hline & BFM2 $56-95$ & 6,5 & 0,24 & 0,14 & 681 & 22 \\
\hline & BC $95-122$ & 6,5 & - & - & 1070 & 22 \\
\hline & C $130-180$ & 7,0 & - & - & 454 & 25 \\
\hline \multirow{10}{*}{$\begin{array}{l}\text { Разрез 463. Стратозем серогумусовый } \\
\text { супесчано-песчаный на погребенной } \\
\text { почве (ржавоземе супесчаном) }\end{array}$} & AY $0-4$ & 6,3 & 3,16 & 1,83 & 564 & 175 \\
\hline & AY $4-14$ & 5,7 & 2,33 & 1,35 & 329 & 50 \\
\hline & R $20-40$ & 6,5 & 0,69 & 0,40 & 514 & 34 \\
\hline & $\mathrm{R} 40-72$ & 6,8 & 0,31 & 0,18 & 681 & 38 \\
\hline & $\mathrm{R} 72-76$ & 7,0 & - & - & 464 & 25 \\
\hline & R 76-106 & 7,2 & - & - & 471 & 25 \\
\hline & [A] $106-120$ & 7,0 & Не опр. & Не опр. & 123 & 22 \\
\hline & {$[\mathrm{BF}] 120-146$} & 6,8 & Не опр. & Не опр. & 576 & 13 \\
\hline & {$[\mathrm{BC}] 148-170$} & 6,9 & Не опр. & Не опр. & 588 & 16 \\
\hline & C $170-184$ & 7,1 & Не опр. & Не опр. & 579 & 15 \\
\hline \multirow{7}{*}{$\begin{array}{l}\text { Разрез 469. ТПО. Квазизем серогумусо- } \\
\text { вый супесчаный (урбиквазизем) }\end{array}$} & AY $1-15$ & 6,1 & 3,00 & 1,74 & 322 & 105 \\
\hline & RY $15-30$ & 6,5 & 2,59 & 1,50 & 259 & 46 \\
\hline & RY $30-48$ & 6,9 & 1,76 & 1,02 & 368 & 36 \\
\hline & R1 $48-75$ & 7,1 & 0,72 & 0,42 & 445 & 17 \\
\hline & R2g $75-91$ & 7,5 & 0,46 & 0,27 & - & - \\
\hline & TURg $91-130$ & 7,5 & 0,22 & 0,13 & - & - \\
\hline & Cca $130-200$ & 7,5 & - & - & - & - \\
\hline
\end{tabular}




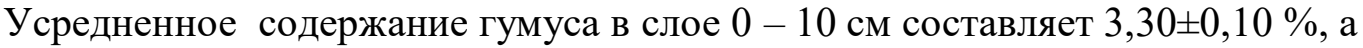
в слое $0-20$ см соответственно 2,82 $\pm 0,25 \%$. Для техногенно-преобразованных почв количественная оценка содержания гумуса (органического вещества) практически не разработана. Можно сравнить содержание гумуса в изученной парковой зоне с таковым в лесных экосистемах Калининградской области с преобладанием лиственных пород. Гумусированность почв парковой зоны пгт Янтарный имеет значения в интервале $3-4 \%$, типичные и для лесных экосистем региона на легких почвообразующих породах в условиях нормального увлажнения [12].

Содержание фосфора в гумусовых горизонтах всех изученных почв на уровне или выше 250 мг/кг, что оценивается как очень высокое. С глубиной количество подвижных фосфатов может немного снижаться (оставаясь в границах высокого содержания), но в большинстве случаев оно значительно увеличивается. При этом надо отметить, что пробы из карбонатных горизонтов в анализ не включались, потому что метод Кирсанова для них не пригоден.

Высокий фосфатный фон почв парковой зоны пгт Янтарный объясняется наличием фосфоритов в почвообразующих породах. Это явление было описано нами раньше [11], является типичным для западной части Калининградской области и подтверждается минералогическим составом проб в работе А. А. Завалишина и Б. В. Надеждина [12, с. 19, 32].

Распределение подвижного фосфора по профилю почв неоднозначное. Часто оно более или менее равномерное или увеличивающееся книзу в насыпных или аккумулированных слоях. Местами встречаются резкие скачки свыше 1000 мг/кг фосфатов (разрез 541, горизонт С 235-250 см; разрез 462, горизонт ВC 95-122 см). Обращает на себя внимание также факт резкого снижения количества подвижного фосфора в гумусовых горизонтах погребенных почв (разрезы 448, $451,463)$. Это объясняется биологическим поглощением под пологом древесных экосистем прошлого. В последующем, после погребения этих почв, горизонты были законсервированы. В условиях близкой к нейтральной реакции среды подвижность фосфатов мала, поэтому факт биогенного выноса фосфора сохранился.

Содержание подвижного калия в гумусовых горизонтах почв варьирует от очень высокого (в разрезах 447, 448) до повышенного (в разрезах 451, 463) и среднего (в разрезах 462, 469). Максимальное содержание калия в почвах приурочено к горизонту дернины, что указывает на биогенную аккумуляцию элемента и его накопление из разлагающегося растительного опада. Распределение подвижного калия по профилю почв резко убывающее. В большинстве случаев на глубинах свыше 40 см содержание калия очень низкое (менее 40 мг/кг). Это связано с преобладанием в рекреационной зоне песков и супесей, которые бедны илистыми частицами и содержат малое количество (менее 5 - 7 \%) физической глины (сумма частиц $<0,01$ мм).

Таким образом, оптимальным плодородием в парковой экосистеме обладают только горизонты дернины. В иллювиальных горизонтах, почвообразующей породе и стратифицированных слоях выражен дисбаланс элементов: при очень высоком содержании подвижных фосфатов крайне низкое количество подвижного калия.

Для решения задачи эколого-токсикологической оценки почв мы определили содержание подвижных форм тяжелых металлов и валовой ртути в гумусовых горизонтах почв (табл. 2). Согласно действующим нормам предельно допустимая концентрация (ПДК) подвижных форм ТМ в почвах составляет (мг/кг): 
для $\mathrm{Cu} 3,0$, для $\mathrm{Zn}-23$, для $\mathrm{Pb}-6,0$, для $\mathrm{Ni}-4,0$, для $\mathrm{Cr}(3+)$ - 6,0 [9]. ПДК для подвижного кадмия не определено. ПДК для валового содержания ртути 2,1 мг/кг. Из результатов анализа следует, что нормативы для всех ТМ в изученных почвах не превышены. По степени загрязнения почвы относятся к 1-й группе (содержание ТМ менее 0,5 ПДК) [10] и являются экологически безопасными по данным показателям.

Таблица 2. Содержание подвижных форм тяжелых металлов и валовой $\mathrm{Hg}$ в гумусовом горизонте почв

Table 2. Content of mobile forms of heavy metals and gross $\mathrm{Hg}$ in the humus horizon of soils

\begin{tabular}{|c|c|c|c|c|c|c|c|c|}
\hline Рa3- & Горизонт, & \multicolumn{7}{|c|}{ Тяжелые металлы, мг/кг } \\
\cline { 3 - 9 } рез & глубина, см & $\mathrm{Cu}$ & $\mathrm{Zn}$ & $\mathrm{Pb}$ & $\mathrm{Cd}$ & $\mathrm{Ni}$ & $\mathrm{Cr}(3+)$ & $\mathrm{Hg}$ \\
\hline 447 & AYur 1 - 10 & 0,18 & 1,8 & 0,57 & 0,066 & 1,00 & 0,15 & 0,022 \\
\hline 448 & AYur 1 - 10 & 0,15 & 2,3 & 1,05 & 0,080 & 1,80 & 0,19 & 0,025 \\
\hline 451 & AY 1 - 10 & 0,15 & 4,8 & 1,35 & 0,050 & 0,80 & 0,17 & 0,015 \\
\hline 452 & AY1 - 20 & 0,18 & 1,9 & 1,22 & 0,070 & 0,71 & 0,17 & 0,012 \\
\hline 453 & AY 1 - 6 & 0,21 & 1,2 & 1,00 & 0,070 & 0,80 & 0,17 & 0,034 \\
\cline { 2 - 9 } & AY 6-30 & 0,19 & 0,5 & 0,61 & 0,035 & 0,49 & 0,15 & 0,030 \\
\hline 462 & AY 0 - 5 & 0,27 & 3,9 & 0,92 & 0,050 & 0,47 & 0,17 & 0,012 \\
\hline 463 & AY 0 - 4 & 0,26 & 4,3 & 0,87 & 0,080 & 0,42 & 0,15 & 0,012 \\
\cline { 2 - 9 } & AY 4-14 & 0,23 & 2,3 & 1,40 & 0,060 & 0,28 & 0,18 & 0,011 \\
\hline 469 & AY 1 - 15 & 0,19 & 1,8 & 1,48 & 0,040 & 0,20 & 0,20 & 0,012 \\
\hline
\end{tabular}

\section{ВЫВОДЫ}

1. Реакция среды в почвах парковой рекреационной зоны находится в интервале от слабокислой до нейтральной. Это оптимальные значения для большинства древесных, кустарниковых и травянистых видов растительного покрова. В пяти из восьми изученных почв обнаружены карбонатные горизонты с щелочным pH на глубине свыше 100 см.

2. Несмотря на разнообразный генезис почв, максимальное количество гу-

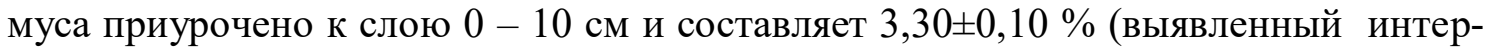
вал $3,00-4,45 \%$ по гумусу или $1,74-2,58 \%$ по органическому углероду). Эти величины являются типичными для лесных почв на супесчаных и песчаных породах в автоморфных условиях региона.

3. Распределение гумуса по профилю зависит от генезиса и варьирует от резко убывающего до равномерно убывающего. Примерно половина изученных почв и почвогрунтов имеет погребенные профили разной сохранности. Содержание органического вещества в гумусовых горизонтах погребенных почв варьирует в пределах от 1,19 до 3,99 \%. Профили с погребенными почвами имеют бимодальное распределение гумуса.

4. Почти для всех почв характерно очень высокое содержание подвижного фосфора (более 250 мг/кг) как в гумусовых горизонтах, так и в почвообразующих породах. Это объясняется примесью фосфоритов и является геохимической особенностью пород Замландского п-ова.

5. Количество подвижного калия максимально в гумусовых горизонтах (100-278 мг/кг). Распределение калия по профилю резко убывающее. Почвообразующие песчаные породы имеют очень низкое содержание подвижного калия. 
6. Анализ подвижных форм тяжелых металлов ( $\mathrm{Cu}, \mathrm{Zn}, \mathrm{Pb}, \mathrm{Cd}, \mathrm{Ni}, \mathrm{Cr}(3+))$ и валовой ртути показал, что содержание этих элементов находится в количествах ниже 0,5 ПДК.

\section{СПИСОК ИСПОЛЬЗОВАННЫХ ЛИТЕРАТУРНЫХ ИСТОЧНИКОВ}

1. Soils in the Urban Environment. Edited by P. Bullock and P.J. Gregory. Blackwell Scientific Publications.1991. 174 p.

2. Fu W., Dao L. Heavy Metalls Pollution in Urban Soils. Scholars' Press. 2017. $228 \mathrm{p}$.

3. Urban Soils. Edited by Rattan Lal, B. A. Stewart. CRC Press Published. 2017. $55 \mathrm{p}$.

4. Станченко, Л. Ю. Типология и эколого-геохимическая оценка урбоэкосистем Калининградской области: автореф. дис... канд. геогр. наук: 25.00.36 Геоэкология / Л. Ю. Станченко. - Калининград, 2009. - 24 с.

5. Анциферова, О. А. Морфологическое строение и классификационная принадлежность почв морского побережья в окрестностях пгт Янтарный / О. А. Анциферова, О. Ю. Чиянова // Известия Калининградского государственного технического университета. - 2019. - № 55. - С. 22 - 35.

6. Классификация и диагностика почв России / сост. Л. Л. Шишов, В. Д. Тонконогов, И. И. Лебедева, М. И. Герасимова. - Смоленск: Ойкумена, 2004. - 342 c.

7. Руководящий документ. Методические указания. Методика выполнения измерений массовой доли подвижных форм металлов (меди, свинца, цинка, никеля, кадмия, кобальта, хрома, марганца) в пробах почвы атомно-абсорбционным анализом в лабораториях Общегосударственной службы наблюдения и контроля загрязнения природной среды. РД 52.18.289-90. - Москва, 1991. - 35 с.

8. ПНД Ф 16.2.2:2.3:3.25-02. Количественный химический анализ почв. Методика выполнения измерений содержания ртути общей в твердых и жидких отходах производства и потребления, осадках, шламах, активном иле, донных отложениях атомно-абсорбционным методом (с Изменением N 1). - Москва, 2017. $-18 \mathrm{c}$.

9. ГН 2.1.7.2041-06. Гигиенические нормативы. Предельно допустимые концентрации (ПДК) химических веществ в почве. - Москва, 2006. - 5 с.

10. Методические указания по проведению комплексного мониторинга плодородия почв земель сельскохозяйственного назначения / под ред. Л. М. Державина, Д. С. Булгакова. - Москва: ФГНУ «Росинформагротех», 2003. - 240 с.

11. Анциферова, О. А. Валовой фосфор в почвообразующих породах и почвах западной части Калининградской области / О. А. Анциферова // Агрохимический вестник. - 2014. - № 2. - С. 11-13.

12. Завалишин, А. А. Почвенный покров Калининградской области / А. А. Завалишин, Б. В. Надеждин // Почвы Калининградской области. - Москва: Изд-во АН СССР, 1961. - С. 5-130. 


\section{REFERENCES}

1. Soils in the Urban Environment. Edited by P. Bullock and P.J. Gregory. Blackwell Scientific Publications, 1991, 174 p.

2. Fu W., Dao L. Heavy Metalls Pollution in Urban Soils. Scholars' Press, 2017, $228 \mathrm{p}$.

3. Urban Soils. Edited by Rattan Lal, B. A. Stewart. CRC Press Published. 2017, $55 \mathrm{p}$.

4. Stanchenko L. Yu. Tipologiya $i$ ekologo-geokhimicheskaya otsenka urboekosistem Kaliningradskoy oblasti. Avtoreferat diss. kand. geogr. nauk [Typology and ecological-geochemical assessment of urban ecosystems of the Kaliningrad region. Abstract of dis. cand. Sci.]. Kaliningrad, 2009, 24 p.

5. Antsiferova O. A., Chiyanova O. Yu. Morfologicheskoye stroyeniye i klassifikatsionnaya prinadlezhnost' pochv morskogo poberezh'ya v okrestnostyakh pgt. Yantarnyy [Morphological structure and classification of soils belonging to the sea coast in the vicinity of the village Yantarny]. Izvestiya KGTU, 2019, no. 55, pp. $22-35$.

6. Klassifikatsiya i diagnostika pochv Rossii [Classification and diagnostics of Russian soils]. Smolensk, Oykumena, 2004, 342 p.

7. Rukovodyashchiy dokument. Metodicheskiye ukazaniya. Metodika vypolneniya izmereniy massovoy doli podvizhnykh form metallov (medi, svintsa, tsinka, nikelya, kadmiya, kobal'ta, khroma, margantsa) v probakh pochvy atomno-absorbtsionnym analizom v laboratoriyakh Obshchegosudarstvennoy sluzhby nablyudeniya i kontrolya zagryazneniya prirodnoy sredy. RD 52.18.289-90 [Guidance document. Methodical instructions. Method of performing measurements of the mass fraction of mobile forms of metals (copper, lead, zinc, nickel, cadmium, cobalt, chromium, manganese) in soil samples by atomic absorption analysis in laboratories of the National service for monitoring and control of environmental pollution. RD 52.18.289-90]. Moscow, 1991, 35p.

8. PND F 16.2.2:2.3:3.25-02. Kolichestvennyy khimicheskiy analiz pochv. Metodika vypolneniya izmereniy soderzhaniya rtuti obshchey $v$ tverdykh $i$ zhidkikh otkhodakh proizvodstva $i$ potrebleniya, osadkakh, shlamakh, aktivnom ile, donnykh otlozheniyakh atomno-absorbtsionnym metodom (s Izmeneniyem N 1) [PND F 16.2.2: 2.3: 3.25-02. Quantitative chemical analysis of soils. Methodology for measuring the total mercury content in solid and liquid wastes of production and consumption, sediments, sludge, activated sludge, bottom sediments by atomic absorption method (with Change N 1)]. Moscow, 2017, $18 \mathrm{p}$.

9. GN 2.1.7.2041-06. Gigiyenicheskiye normativy. Predel'no dopustimyye kontsentratsii (PDK) khimicheskikh veshchestv v pochve [GN 2.1.7.2041-06. Hygienic standards. Maximum allowable concentration (MPC) of chemicals in the soil]. Moscow, 2006, 5 p.

10. Metodicheskiye ukazaniya po provedeniyu kompleksnogo monitoringa plodorodiya pochv zemel' sel'skokhozyaystvennogo naznacheniya [Guidelines for the comprehensive monitoring of soil fertility of agricultural lands]. Moscow, FGNU "Rosinformagrotekh", 2003, $240 \mathrm{p}$.

11. Antsiferova O. A. Valovoy fosfor $v$ pochvoobrazuyushchikh porodakh i pochvakh zapadnoy chasti Kaliningradskoy oblasti [Gross phosphorus in parent rocks and soils of the western part of the Kaliningrad region]. Agrokhimicheskiy vestnik, 2014, no. 2 , pp. 1-13. 
12. Zavalishin A. A., Nadezhdin B. V. Pochvennyy pokrov Kaliningradskoy oblasti [Soil cover of the Kaliningrad region]. Pochvy Kaliningradskoy oblasti [Soils of the Kaliningrad region]. Moscow, Izd-vo AN SSSR, 1961, pp. 5-130.

\section{ИНФОРМАЦИЯ ОБ АВТОРАХ}

Анщиферова Ольга Алексеевна - Калининградский государственный технический университет; кандидат сельскохозяйственных наук, доцент;

E-mail: anciferova@inbox.ru

Antsiferova Olga Alekseevna - Kaliningrad State Technical University;

$\mathrm{PhD}$ in Agricultural Sciences, Associate Professor; E-mail: anciferova@inbox.ru

Чиянова Ольга Юрьевна - Калининградский государственный технический университет; аспирант факультета биоресурсов и природопользования

Chiyanova Olga Yurievna - Kaliningrad State Technical University; postgraduate students at the Faculty of bioresources and environmental management 